\title{
Assessment of soil physical health and productivity of Kharkhoda and Gohana blocks of Sonipat district (Haryana), India
}

\author{
Rakesh Kumar*, Pramila Aggarwal, Ravendra Singh, Debashis Chakraborty, Ranjan \\ Bhattacharya, R. N. Garg, Kalpana H. Kamble and Brijesh Yadav
}

Division of Agricultural Physics, Indian Agricultural Research Institute, New Delhi-110012, INDIA

*Corresponding author. E-mail: rbinnu@gmail.com

Received: November 6, 2013; Revised received: January 2, 2014; Accepted: January 5, 2014

\begin{abstract}
In order to assess soil health of Kharkhoda and Gohana blocks of Sonipat district (a part of western Yamuna canal irrigated region), important parameters namely $\mathrm{pH}$, electrical conductivity (EC), texture, bulk density $(B D)$, saturated hydraulic conductivity $(\mathrm{HC})$, soil organic carbon $(\mathrm{OC})$, available water retension capacity (AWRC) and non capillary pores (NCP) were measured by collecting undisturbed soil samples in nearly 66 villages. Soil physical rating index $(\mathrm{PI})$ method was used to compute $\mathrm{PI}$ which was an indicator of soil physical health of that region. Results revealed that in Gohana and Kharkhoda blocks, nearly $90 \%$ area had $\mathrm{pH}<8.0$ and $\mathrm{EC}>4 \mathrm{dS} \mathrm{m} \mathrm{m}^{-1}$, which indicated that soils were saline. Prediction maps of soil BD showed that $75 \%$ of the total area in $15-30 \mathrm{~cm}$ soil layer had $\mathrm{BD}$ above $>1.6 \mathrm{mg} \mathrm{m}^{-3}$, which indicated the presence of hard pan in subsurface. HC data of subsurface layer also showed that $60 \%$ of the area had values $<0.5 \mathrm{~cm} \mathrm{hr}^{-1}$ which reconfirmed the presence of hard pan. For both surface as well as subsurface soil layers, mostly AWC was $>10 \%$ which indicated adequate water retention capacity of these soils. However $85 \%$ of subsurface had poor soil aeration capacity as indicated NCP range $<10 \%$. Prediction map of $\mathrm{PI}$ for subsurface layer showed that majority of area had $\mathrm{Pl}<0.4$ which indicated that expected yield of the crop cannot be more than $70 \%$ of the potential yield even under normal or higher levels of fertilizer and water inputs.
\end{abstract}

Keywords: Soil physical health, Soil physical rating index, Sub surface compaction

\section{INTRODUCTION}

As the soil is continuously cultivated, soil degradation processes such as soil erosion, nutrient depletion, compaction, salinization are set in motion, triggering deterioration of soil structure and depletion of organic carbon (Kong et al., 2005). Generally, high resilient state of the soil restores the soil productivity fast provided soil fatigue is not too much i.e disturbance created by human activity is not too drastic (Lal, 1994). In other words, amplitude of degradation and its restoration of soil depends not only soil inherent characteristics but also on magnitude, intensity and duration of stress such as high compaction level, low plant water availability, reduction in aggregate stability due to low soil OC level (Haynes, 2005).

Since the quantitative assessment of soil physical health is difficult, hence for its qualitative evaluation, various indices have been developed. The productivity index model developed by Neill (1979) was used to evaluate soil productivity in the top $100 \mathrm{~cm}$. The model rated soils on potential available water storage capacity, bulk density, aeration, $\mathrm{pH}$ and electrical conductivity. A value from zero to one is assigned to each property describing the importance of that parameter for root development. The product of these five index values is used to describe the fractional sufficiency of any soil layer for root development. Accordingly, the production potential of these soils was predicted under optimum levels of water and fertilizer inputs along with the adoption of appropriate plant protection measures. Soil physical rating index (PI) developed by Gupta (1986) was another index which was used for identification of soil physical constraints (Aggarwal and Chaudhary, 2005). Site-specific crop and soil management often incorporates precise spatial information about soil properties across farmfields to help meet the goal of optimizing inputs use while maintaining or increasing yields (Huang and Jin, 2002; Huang et al., 2006). The present study was conducted in farmers' fields in Gohana and Kharkhoda blocks of Sonipat districts of Haryana (part of trans-indogangetic plain) to monitor soil physical health and productivity.

\section{MATERIALS AND METHODS}

Study area: The present study was conducted in Gohana and Kharkhoda block (Fig. 1) of Sonipat district in Haryana, India, located at $28^{\circ} 47^{\prime} 26.959^{\prime \prime}$ to $29^{\circ} 11^{\prime} 55.306^{\prime \prime}$ North latitude and $76^{\circ} 37^{\prime} 47.601$ ' to 77³'10.875" East longitudes. Gohana and Kharkhoda 


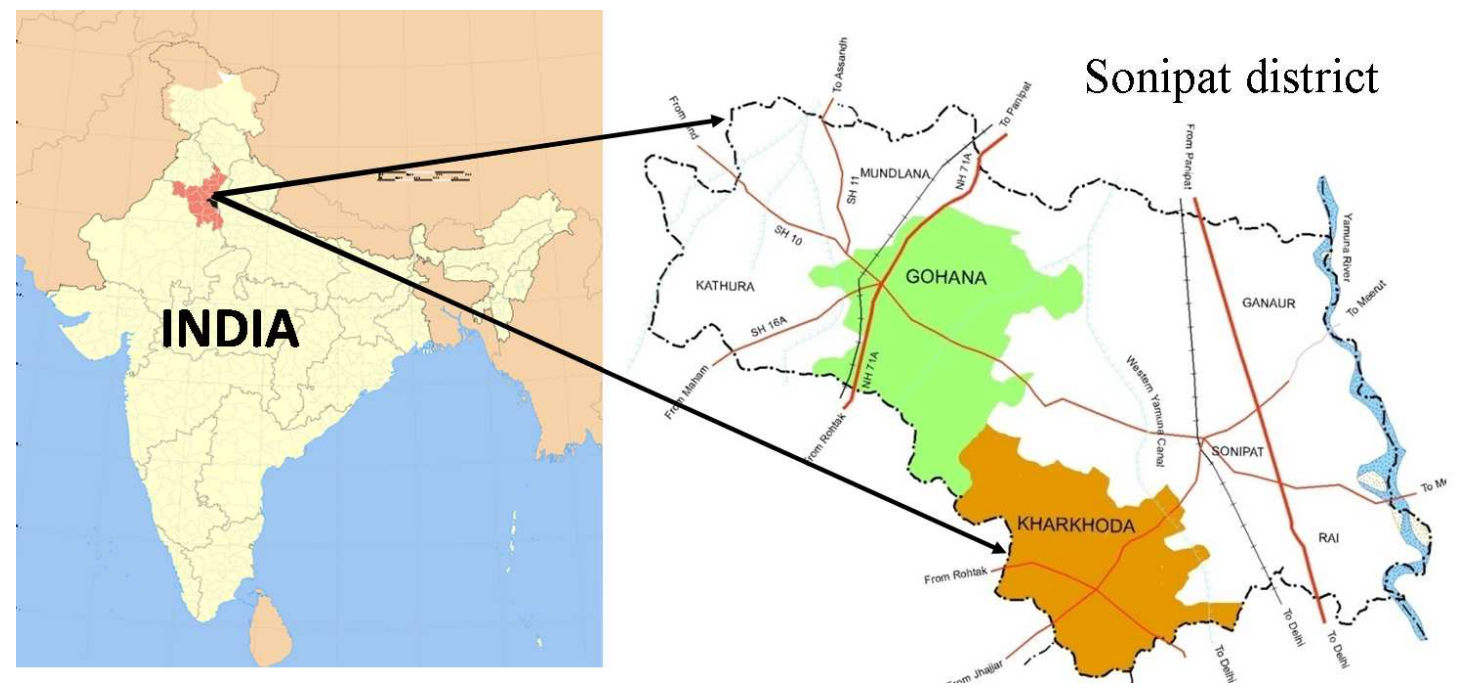

Fig. 1. Map of Gohana and Kharkhoda block of Sonipat district of Haryana.

in Sonipat district is a part of the Eastern Haryana plain (Trans Indo-Gangetic Alluvial plains). The climate of the district is characterized by the dryness of the air with an intensely hot summer and a cold winter. The mean annual rainfall of the district was $624 \mathrm{~mm}$, $76 \%$ of the annual rainfall is received during the south-west Monsoon from July-September and the rest was received through 'Western Disturbances' from December to February (Anonymous, 2008).

Analysis of soil properties: Soil samples were taken at the harvest of wheat crop by core auger for determination of soil properties such as $\mathrm{pH}$ by $\mathrm{pH}$ meter, electrical conductivity (EC) determined by EC meter, bulk density (BD) by Core method, soil texture by international pipette method, soil organic carbon by Walkley and Black (1934) method and saturated hydraulic conductivity (HC) by constant head

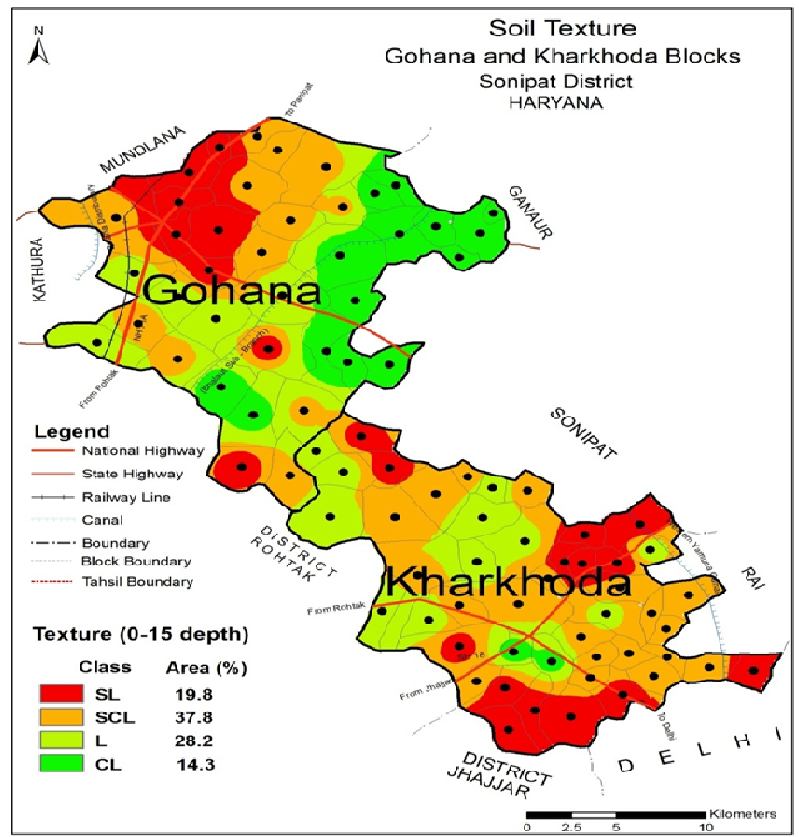

permeameter method (Klute and Dirksen, 1986). Field capacity and wilting point were determined by pressure plate apparatus.

Soil physical rating index (PI): Computation of PI involved measurement of important physical properties such as soil depth, bulk density, infiltration rate, soil organic matter, available water storage capacity, non capillary pore space, land slope and water table depth. For a given site, each of these parameters was assigned a rating value corresponding to its actual value by referring to rating chart (Gupta, 1986). Each of this parameter was given a score of 1 if the parameter value lies within the optimum range. If the value lies below or above the critical limit, a score less than 1 were given. Greater the deviation of parameter value from optimum range, lesser the score given to it. The product of rating values of all the eight parameters

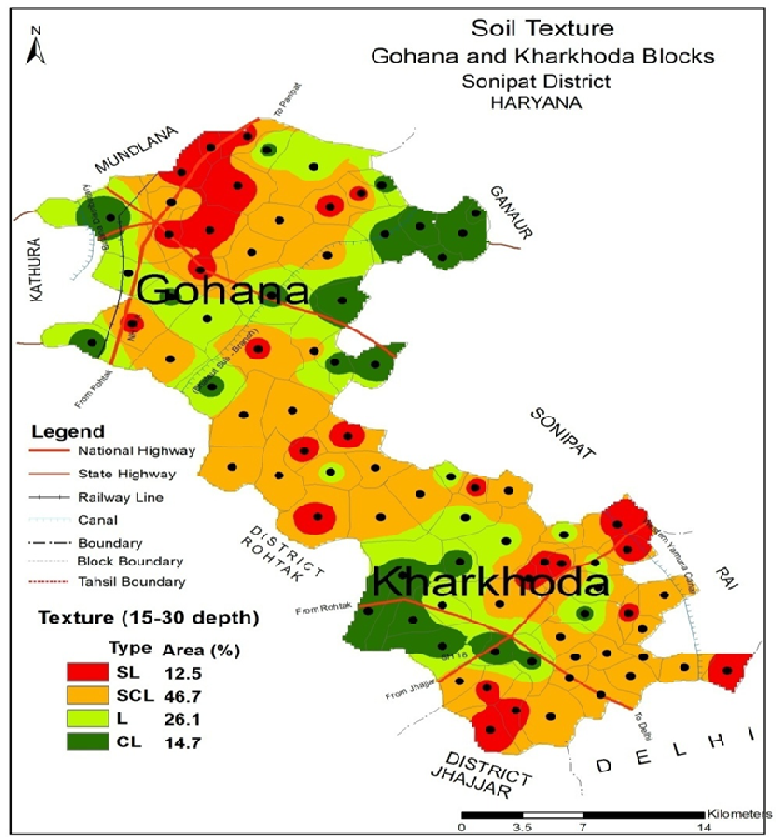

Fig. 2. Map of soil texture distribution under Gohana and Kharkhoda block of Sonipat ( Haryana). 
gave the physical rating index. PI was an indicator of overall soil physical health status. For range of PI $>0.75,0.50-0.75,0.25-0.50$ and $<0.25$, soil physical health status and accordingly its production potential could be labeled as very good, good, medium or poor, respectively.

Preparation of prediction maps: Maps for the study area were prepared using geo processing tools of ArcGIS software. To prepare prediction maps, firstly three vector shape files- one point file (for preparing data attribute table), one line file (for showing roads and canal) and two polygon files (for showing block boundary and village boundaries) were created in Arc Catalogue and were added to a new Arc Map. In next step, scanned map of Gohana and Kharkhoda block was geo referenced in Arc Map. After that, vector files were digitizing for Gohana and Kharkhoda block i.e. block boundary, 66 village boundaries, roads, rivers and canals. Sampled data points, collected using GPS (Global positioning system) with latitude and longitude for each location, were digitized and added in the map as an attribute table. All the measured and computed soil properties and indices were added as separate fields in this attribute table and prediction maps (smooth 2D-surfaces) of each property was generated using most widely used interpolation technique - inverse distance weighting method (IDW) (Franke, 1982). Prediction maps are actually filled contour maps showing different ranges of the given parameter with different colours. Values of BD, AWC, $\mathrm{HC}, \mathrm{OC}$ and NCP were divided into ranges similar to those given in physical rating method and appropriate rating values were assigned to them. PI at each sampling point was determined by multiplying the rating values for all five parameters. Reason for multiplication of individual rating values for defining the PI was that this index was an indicator of soil productivity. Large deviation in any of the individual parameter value from its optimum range could bring down the yield drastically and such a response could
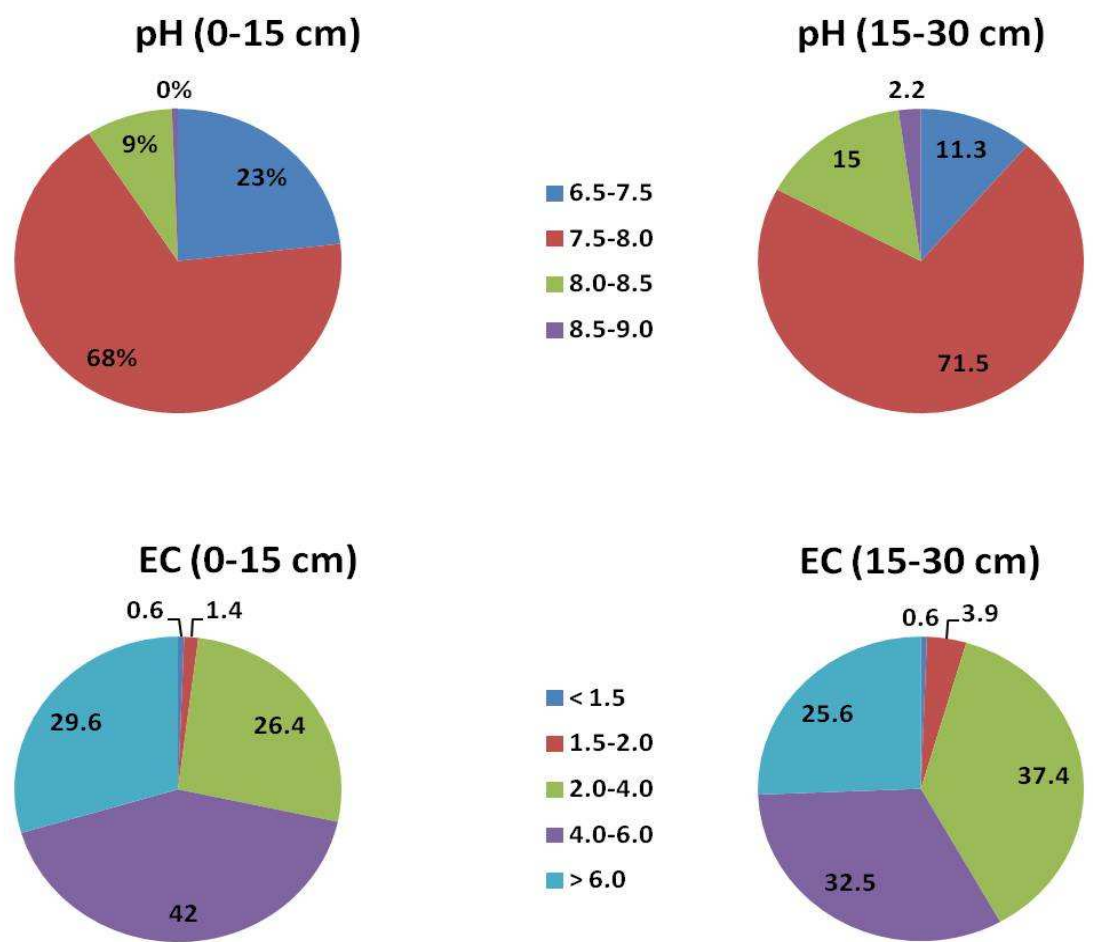

$-6.5-7.5$
$-7.5-8.0$
$-8.0-8.5$
$=8.5-9.0$
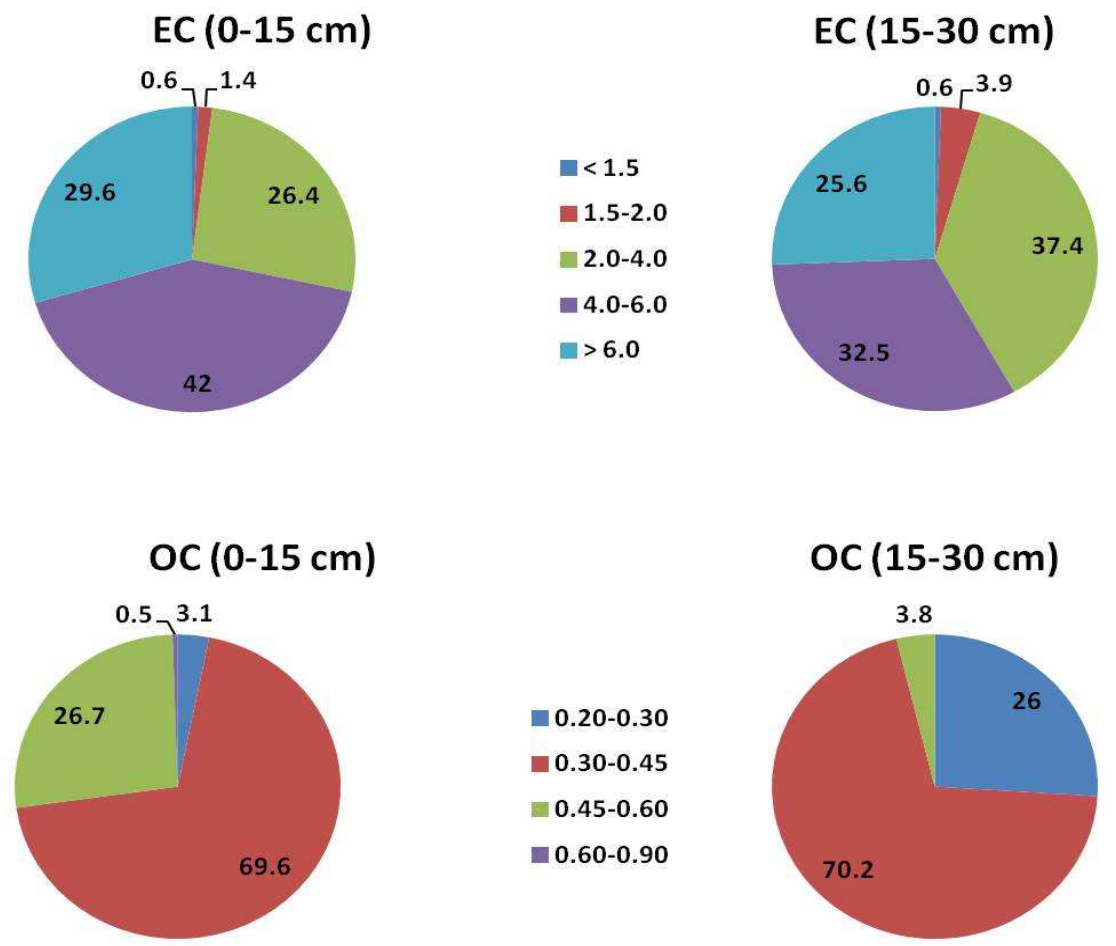

Fig. 3. Percentage distribution of surveyed area under different ranges of soil $\mathrm{pH}, E C$ and $O C$. 


\section{$\mathrm{BD}(0-15 \mathrm{~cm})$}
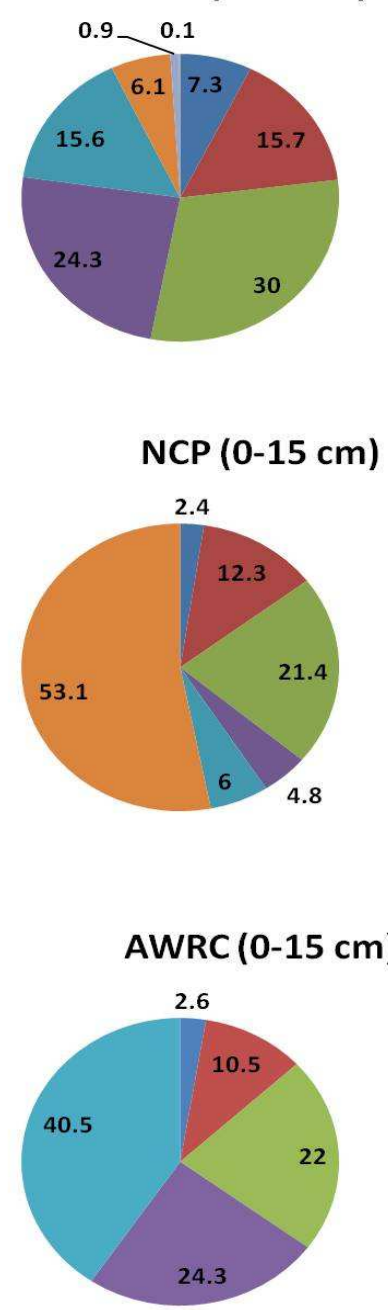

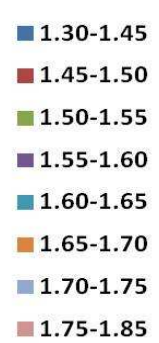

1.75-1.85

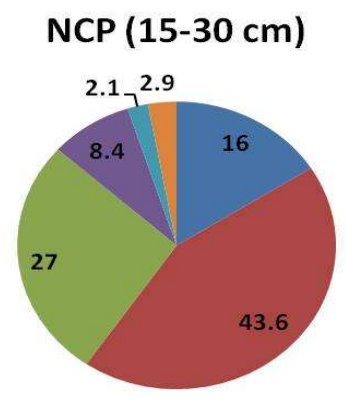

\section{AWRC (15-30 cm)}

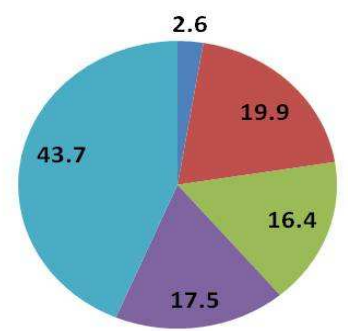

Fig. 4. Percentage distribution of surveyed area under different ranges of soil $B D, N C P$ and $A W R C$.

only be observed if the rating values of individual parameters were multiplied. Lastly, these soil maps were subjected to raster map calculations (based on arithmetic, boolean and relational operators) to compute percentage of total area under different ranges.

\section{RESULTS AND DISCUSSION}

Analysis of soil data of surveyed site revealed that variation of clay and sand was within $4.0-36 \%$ and 36$80 \%$, respectively. Prominent texture classes of the area included sandy loam to clayey loam (Fig. 2). Majority of soils of low lying recent alluvial plains which form the drainage basin of river Yamuna had fine textured soils and a small part which is in the upland plains had coarse textured soil. In most of the area $(90 \%)$, pH was less than 8.0 and EC was less than $>4 \mathrm{dS} \mathrm{m}^{-1}$, which indicated that soils were saline (Fig. 3). OC of both surface and sub-surface layers in majority of area $(88 \%)$ had values ranged between $0.30-0.60 \%$. Range of OC clearly indicated that these areas are deficient in organic carbon and it decreases with depth.

Nearly $30 \%$ of the area had HC value between 5-15 (Fig. 4). Nearly, $60 \%$ of the area of sub-surface soil had values $<0.5 \mathrm{~cm} \mathrm{hr}^{-1}$. Similarly, average bulk density (BD) also varied between optimum $(1.30 \mathrm{mg}$ $\left.\mathrm{m}^{-3}\right)$ to higher $\left(1.85 \mathrm{mg} \mathrm{m}^{-3}\right) .75 \%$ of the total area in $15-30 \mathrm{~cm}$ soil layer had BD above $>1.60 \mathrm{mg} \mathrm{m}^{-3}$, which indicated the formation of compact layer in the sub-surface. Both lower $\mathrm{HC}$ and higher $\mathrm{BD}$ in sub-surface indicated the presence of compact layer. In some areas, both available water retention capacity (AWRC) and non-capillary pores (NCP) were below their optimum ranges (15\% for AWRC and $10 \%$ for NCP). However $85 \%$ of subsurface had poor soil aeration capacity as indicated NCP range $<10 \%$. Prediction map of PI showed that $50 \%$ of area had PI between 0.5-0.6 which indicated that expected yield of the crop will be between $50-60 \%$ of the potential yield under normal levels of fertilizer and water inputs. $25 \%$ of the area had PI between 0.40-0.60 (medium soil physical health and medium). On the other hand for subsurface, majority of area had $\mathrm{PI}<0.4$. Linear 

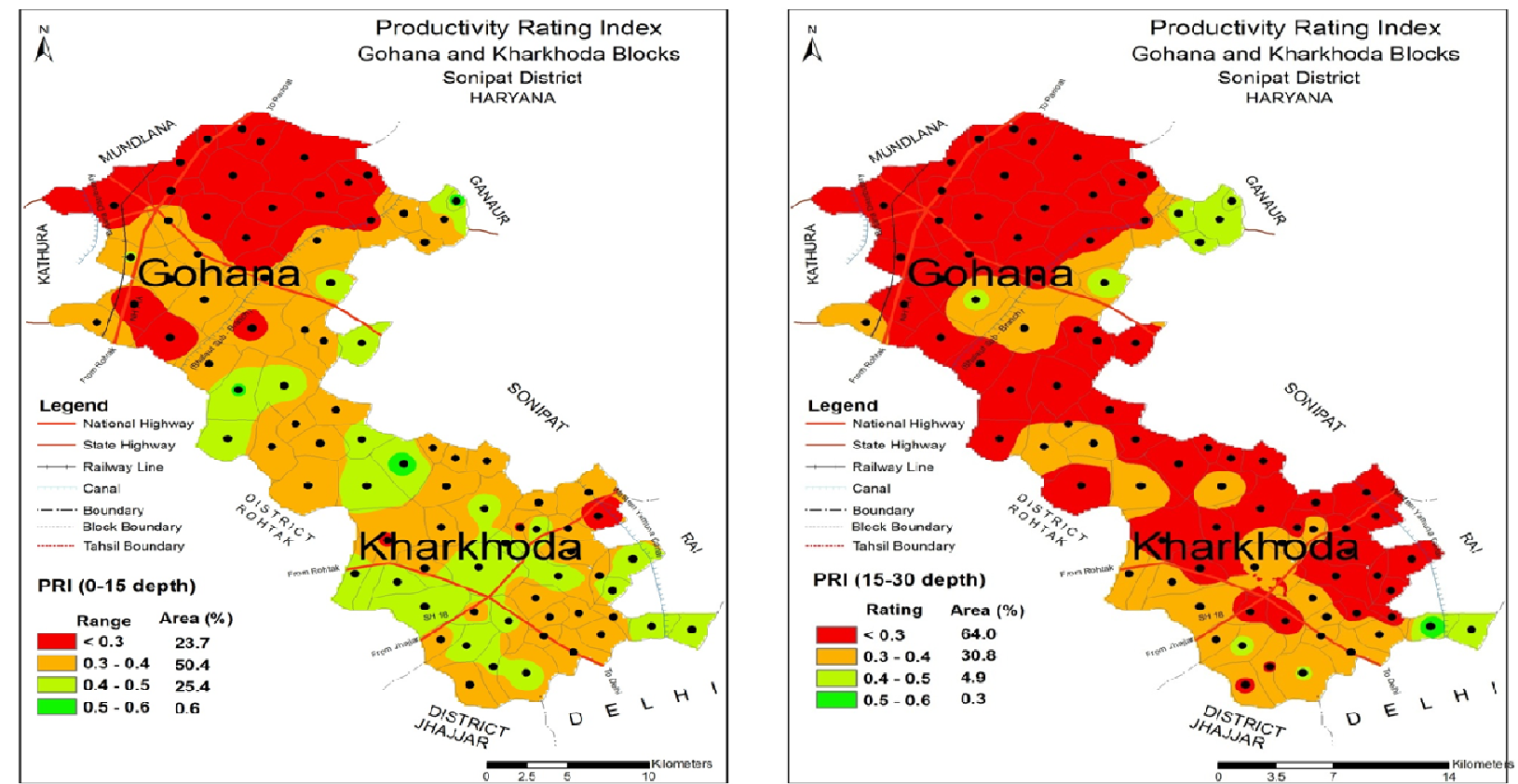

Fig. 5. Prediction map of Productivity Rating Index (PI) under Gohana and Kharkhoda block of Sonipat (Haryana).

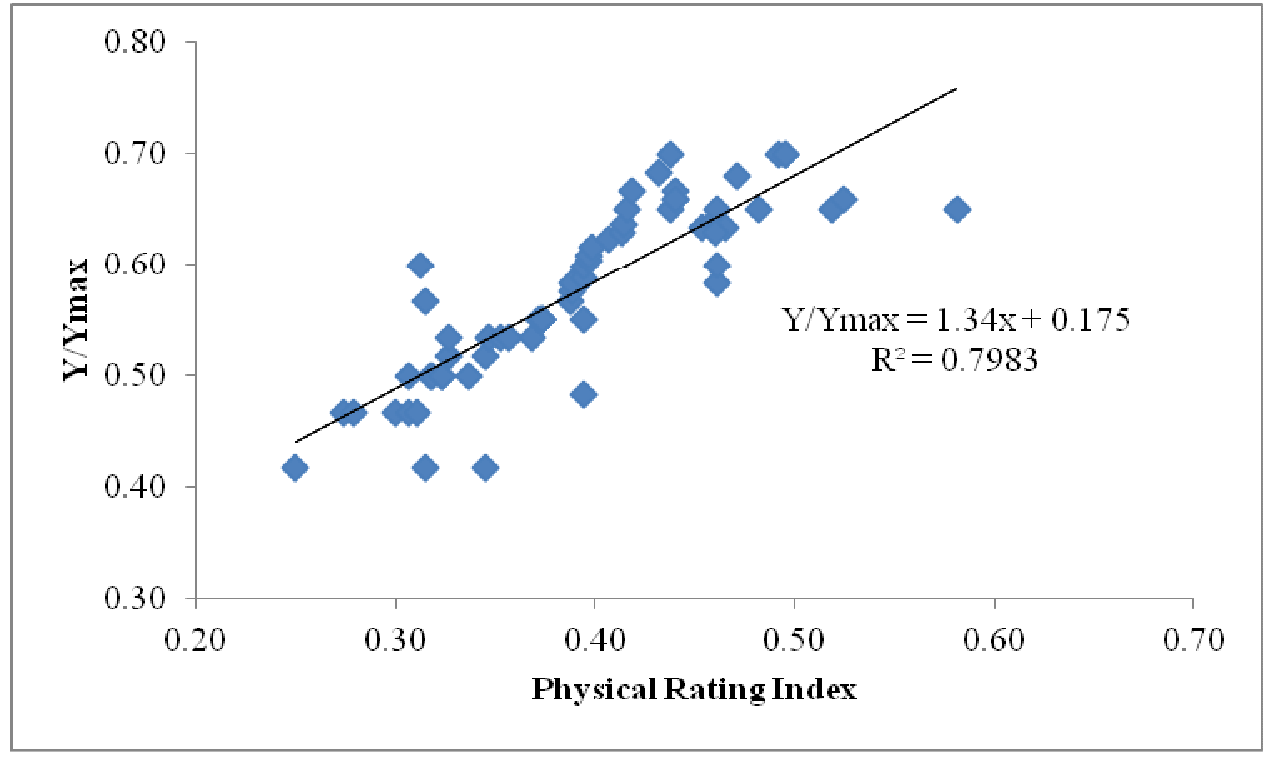

Fig. 6. Correlation between PI and wheat yield of surveyed locations.

regression analysis of PI and production potential of soil (i.e. relative wheat grain yield, $\mathrm{Y} / \mathrm{Y}_{\max }$ ) showed a good correlation $\left(\mathrm{R}^{2}=0.79\right)$ (Fig. 6). The results thus supported earlier findings (Neill, 1979; Pierce et al., 1983; Amirinejad et al., 2011) that good soil physical health is essential for optimum sustained crop production. From the curve, it is clear that $\mathrm{Y} / \mathrm{Y}_{\max }$ is proportional to PI. In another word, one can say production potential of soil decreases with decrease in magnitude of PI. The above linear regression equation between the two variables thus indicated that expected yield of the crop cannot be more than $70 \%$ of the potential yield even under normal or higher levels of fertilizer and water inputs as PI $<0.4$ in subsurface.

\section{Conclusion}

PI method is most suited for soil physical constraint identification and also for accessing the production potential of soils in a given region. Major constraints of soils of Gohana and Kharkhoda were the compaction and poor aeration in subsurface which could be due to intense tilling both in rice and wheat. Beside higher salinity levels were developed in farmers fields probably due to over irrigation because of presence of network of canals in this region. Thus, prediction map of PI of subsurface showed a magnitude $<0.4$ in $94 \%$ of the area which indicated overall poor soil physical health of the region and was mainly responsible for poor crop yields. 


\section{REFERENCES}

Aggarwal, P. and Choudhary, B.U. (2005). Physical rating of soils of Delhi region for assessing their production potential. Indian journal of agricultural sciences, 75: 513-515.

Amirinejad, A.A., Kamble, K.H., Aggarwal, P., Chakraborty, D., Pradhan, S. and Mittal, R.B. (2011). Assessment and mapping of spatial variation of soil physical health in a farm. Geoderma, 160: 292-303.

Anonymous (2008). Groun water information booklet, Sonipat district, Haryana, Central ground water board, Ministry of water resource, Government of India.

Franke, R. (1982). Scattered data interpolation: tests of some methods. Mathematics of Computation, 38:181-200.

Gupta, R. P. (1986). Criteria for physical rating index for soils in relation to crop production. (In) Proceedings of XW International soil science society congress, held at Hemburg, pp, 69-71.

Haynes, R. J. (2005). Labile organic matter fractions as central components of the quality of agricultural soils: an overview. Advances in Agronomy, 85: 221-268.

Huang, S. W. and Jin, J. Y. (2002). Advance in study on spatial variability of soil chemical properties. Soil Fertility, 1: 8-14.

Huang, S. W., Jin, J. Y., Yang, L. P. and Bai, Y. L. (2006). Spatial variability of soil nutrients and influencing factors in a vegetable production area of Hebei Province in China. Nutrient Cycling and Agro ecosystem, 75: 201 -212 .

Klute, A. and Dirksen, C. (1986). Hydraulic conductivity and diffusivity: laboratory measurements. In: Methods of Soil Analysis (ed. A. Klute). 2nd edition, pt. 1, Agron. Monograph No. 9, Madison, WI. pp: 687-734.

Kong, A. Y. Y., Six, J., Bryant, D. C., Denison, R. F. and Van, K. C. (2005). The relationship between carbon input, aggregation, and soil organic carbon stabilization in sustainable cropping system. Soil Science Society of America Journal, 69: 1078-1085.

Lal, R. (1994). Tillage effects on soil degradation, soil resilience, soil quality, and sustainability. Soil Tillage Research, 27: 1-8.

Neill, L. L. (1979). An evaluation of soil productivity based on root growth and water depletion. M. Sc. Thesis. University of Missouri, Columbia, MO.

Pierce, F. J., Larson, W. E., Dowdy, R. H. and Graham, W. A. P. (1983). Productivity of soils: assessing long-term changes due to erosion. Journal of Soil Water Conservation, 38: 39-44.

Walkley, A. and Black, T.A. (1934). An examination of the Degt. Jarett method for determination of soil organic matter and a proposed modification of cromic acid titration. Soil Science, 37: 29-38. 